\title{
Journal of Thermal Spray Technology Announces Increase in Frequency, Experiences Growth in Impact Factor
}

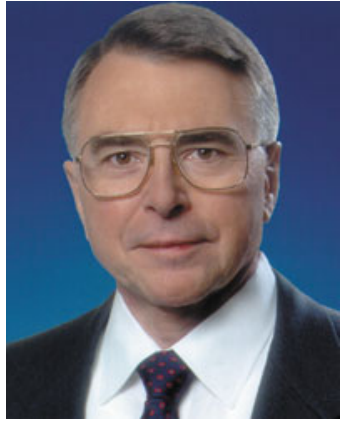

Tucker

Beginning in 2013, the Journal of Thermal Spray Technology (JTST) will increase its frequency from six to eight issues each year. The journal currently publishes four regular issues plus one double issue featuring papers expanded from presentations at the annual International Thermal Spray Conference. This double issue will continue to be published each year, along with six regular issues that will be published on a bimonthly basis.

With the new publishing schedule, authors will experience a reduced average time for their papers to appear in print following OnlineFirst publication, and readers will enjoy more frequent appearance of new content, all with no increase in member subscription price!

JTST began as a quarterly publication in 1992, and added the additional special ITSC double issue in 2007. JTST has consistently increased the

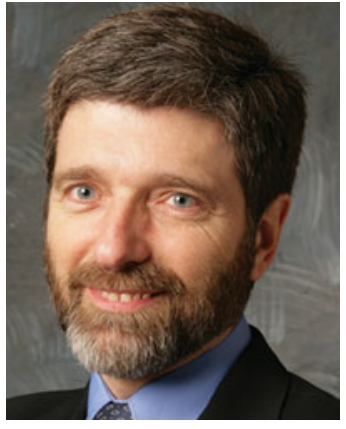

Moreau

number of pages and articles published each year. Increasing frequency is a great sign of growth for the journal, and it enables us to better serve our authors and readers.

At the same time that it has increased in size, JTST has also experienced a growth in Impact Factor. Impact Factor is a measure of the frequency with which the "average article" in a journal has been cited in a particular year. Impact Factors are calculated each year for journals indexed in Thomson Reuters Journal Citation Reports. The annual Impact Factor is a ratio between citations and recent citable items published. Thus, the Impact Factor of a journal is calculated by dividing the number of current year citations to the source items published in that journal during the previous 2 years.

An increase in the number of papers published can therefore in effect

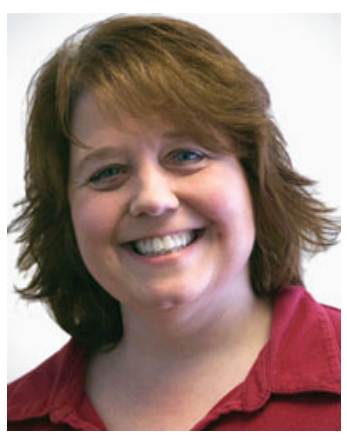

Fleming

"dilute" a journal's Impact Factor. However, JTST has been able to increase the number of papers published while simultaneously showing strong growth in its Impact Factor.

The JTST Impact Factor grew from around 0.6 in 2002 to 1.2 in 2006 through 2008. But last year it jumped to more than 1.8 and remained there this year. This represents a consolidation of the huge increase of the previous year. JTST ranks sixth in the list of 18 journals in the category of "coatings and films."

The JTST editors, assisted by all of those who contribute to JTST, including authors, reviewers, and committee members, have worked very hard to reach these important milestones. We plan to continue to select the very best papers for publication in our journal in order to sustain its growth and quality.
Robert C. Tucker Jr.

Chair, JTST Editorial Committee

\section{Christian Moreau}

Editor-in-Chief, JTST

Mary Anne Fleming

Senior Content Developer, Journals, ASM International 